\title{
Bitkisel Hammaddelerden Elde Edilen Biyodizelin Alternatif Enerji Kaynağı Olarak Kullanılması
}

\author{
Muhammed Said FIDAN*, Elif ALKAN \\ Gümüşhane Üniversitesi, Fen Bilimleri Enstitüsü, Ormancllk ve Çevre Bilimleri ABD, 29000, Gümüşhane,
}

Geliş tarihi/Received 02.01 .2014

Düzeltilerek geliş tarihi/Received in revised form 27.03.2014

Kabul tarihi/Accepted 06.05 .2014

\begin{abstract}
$\ddot{\text { Özet }}$
Yenilenemeyen fosil yakıtların azalması gelişmekte olan ülkelerde yüksek petrol fiyatları şeklinde etkili olmaktadır. Bu durum ülkelerin yeni ve ucuz enerji kaynaklarının araştırılmasının önünü açmaktadır. Türkiye komşu ülkelere oranla enerji arzını oldukça pahalı elde etmektedir. Ülkemizin sağllkl gelişmesi ve sanayileşmesinin önünde duran bu problem acil olarak çözüm beklemektedir. Farklı enerji üretim metotları arasında biyokütle ile tarımsal ve orman atıklardan enerji üretimi Türkiye'nin potansiyeli göz önüne alındı̆̆ında son derece etkin bir şekilde kullanılabilir. En önemli yenilenebilir enerji kaynaklarının başında da biyodizel gelmektedir. Biyodizel; dizel motorlar için, bitkisel ve hayvansal yă̆lar gibi yenilenebilir kaynaklardan üretilebilen alternatif bir yakıttır. Toksik olmayan, doğada kolay bozulabilen, çevreci bir yakıt dostu ve geleneksel dizel motorlarında bazı modifikasyonlarla veya modifikasyona gerek kalmadan kullanılabilmektedir. Bu çalışmada, biyodizel'in alternatif enerji kaynağı olarak üretim miktarları, özellikleri ve avantajları gibi konularda literatür taramaları yapılarak incelenmesi amaçlanmıştır.
\end{abstract}

Anahtar Kelimeler: Enerji, biyodizel, biyokütle, bitkisel yă̆lar

\section{Use As An Alternative Energy Source of Biodiesel Derived From Plant Raw Materials}

\begin{abstract}
Reducing of the nonrenewable energy sources has became role of high price of the gas in developing countries. Due to this new situation, countries paves to study new and cheap energy resources. Turkey is a country that gains the energy much more expensive when compared to Turkey's neighbours. Standing in front of this problem, healthy development and industrialization of our country need to be solved urgently. Among differrent energy production methods, biomass with agricultured forest trash can be used extremely effectively given the potential of Turkey. Biodiesel is one of the most important renewable energy resource. Biodiesel is a fuel type that made of renewable resources like herbal and animal fat. It can be used in Non-toxic, perishable in nature, environmentally friendly engines and a fuel in a conventional diesel engine, with or without some modifications. In this study, biodiesel as an alternative energy source were investigated in terms of its features, advantages and production amount through the literature on such topisc as intended.
\end{abstract}

Keywords: Energy, biodiesel, biomass, vegetable oil

\footnotetext{
${ }^{*}$ M. Said FIDAN, saidfidan@gumushane.edu.tr, Tel: (0456) 2237321
} 


\section{Giriş}

Dünyada enerji gereksinimin \% 90'1 kömür, petrol ve doğalgaz gibi fosil kaynaklı yakıtlardan karşılanmaktadır. Fosil yakıtların dünyada bilinen rezerv dağılımları, petrol eşdeğeri olarak, \% 68 kömür, \% 18 petrol ve \% 14 doğal gaz olarak bilinmektedir (Vogel, 1999). Bununla birlikte sanayileşme ve fosil kaynaklarının aşırı kullanımına bağlı olarak yaşanan çevresel sorunların zaman içerisinde bölgesel ve ülkesel boyuttan uzaklaşarak küresel bir sorun haline gelmesi, hükümetlerin yenilenebilir enerji kaynaklarına bakış açısını değiştirmiştir. Özellikle enerjide dışa bağımlı olan ülkeler için önemli bir firsat olan yeni ve yenilenebilir enerji kaynaklarıyla, yakalanan maliyet avantajlarıyla birlikte, ülkelerin gelişmesinde önemli bir itici unsur durumuna gelmektedir (Demirbaş, 2009).
Şekil 1'de görüldüğü gibi biyokütle içerisinde yer alan biyodizel, hayvansal veya bitkisel yağlar gibi yenilenebilir kaynaklardan elde edilen alternatif bir dizel yakıtıdır. Kimyasal olarak, uzun zincirli yağ asidi mono alkil esteri olarak tanımlanabilir (Alptekin ve Çanakçı, 2006). Biyodizel üretiminin rüzgar ve güneş enerjileri gibi diğer alternatif enerji kaynakları üretimine kıyasla, daha az maliyetli ve kolay üretilebiliyor özellikte olması, üretiminin giderek yaygınlaşmasına katk1 sağlamaktadır. Bununla birlikte, biyodizel üretiminin özellikle tarım, sanayi ve çevre sektörlerinin birlikte çalışmasına olanak vermesi, bu sektörlere ilave istihdam ve gelir olanakları da sağlaması, biyodizel teknolojisinin hızlı gelişmesine neden olmaktadır (Sabancı vd., 2010).

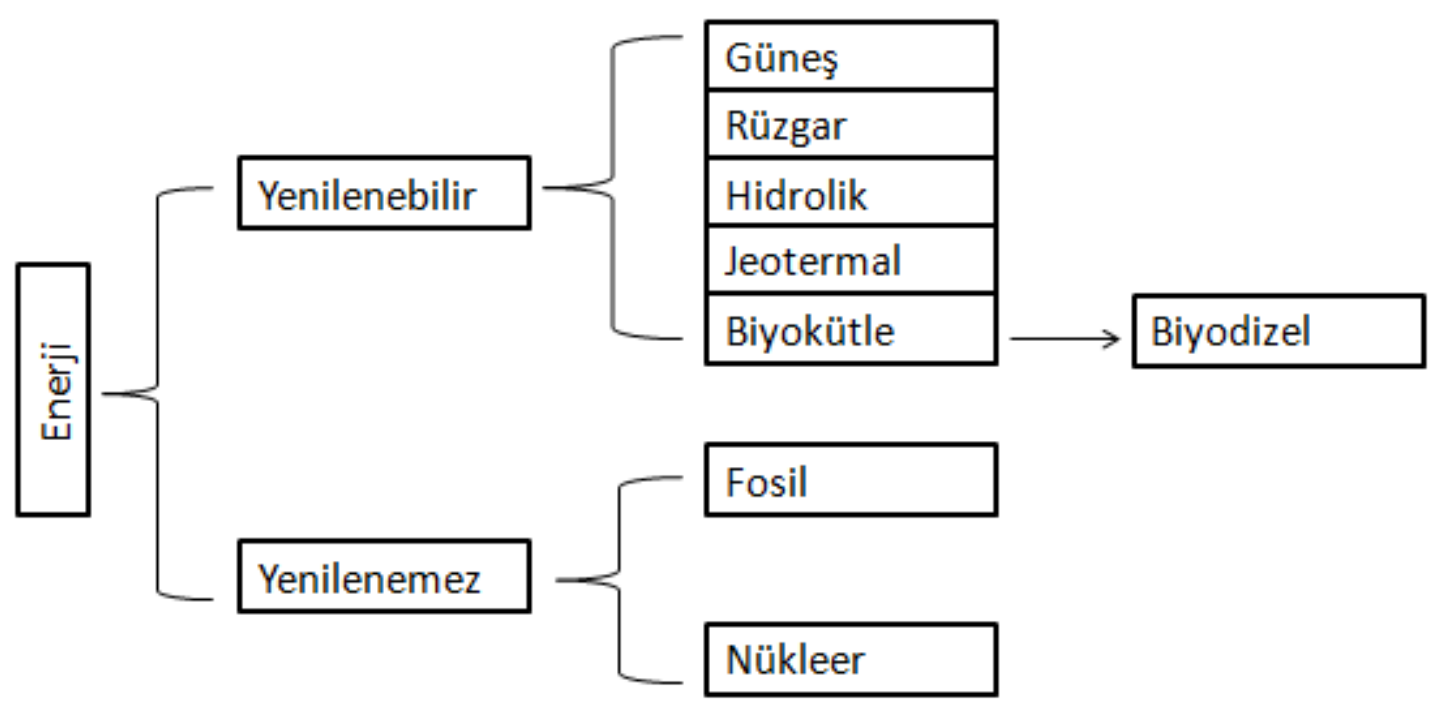

Şekil 1. Yenilenebilir ve yenilenemez enerji kaynakları (Öğüt ve Oğuz, 2006)

Günümüzde benzin ve dizel yakıtına alternatif olarak üretilen yakıtlar etanol ve biyodizeldir. Biyodizel üretimi, özellikle 2000'li yıllardan sonra dünyada ve ülkemizde hız kazanmıştır.

Biyodizel, tarımsal sanayinin güçlenmesini sağlar ve kırsal alandan göçü azaltır, tarımsal ürünlerden ve atıklardan üretilebilir, tarımsal üretimde çeşitliliği sağlayarak ekolojiye olumlu katkıda bulunması ve sürdürülebilir tarımsal yapı oluşturması, çiftçinin üretimine süreklilik kazandırması, yağ bitkileri tarımını yaygınlaştırması aynı zamanda evsel yă açığının kapatılmasına destek olması, ekim nöbetinin yaygınlaştırılarak toprak verimliliğinin arttırılması gibi günümüzün birçok derdine deva olabilecek özellikleri içinde barındırmaktadır (URL 1, 2013).

\section{Dünya'da ve Türkiye'de Enerji Kaynaklarının Bugünkü Durumu}

Yeryüzündeki bütün enerjilerin kaynağı olarak güneş enerjisi kabul edilmektedir. 
Nitekim bitkiler hidrokarbonlar yoluyla güneş enerjisini, kimyasal enerjiye dönüştürürler. Fosil yakıtlar milyonlarca yılda oluşabildiği halde, biyoyakıtlar birkaç ay gibi kısa bir sürede üretilebilir.

Tüm dünyanın küresel 1sınmayla mücadele ettiği, aynı zamanda büyüyen enerji ihtiyacını karşılamak için alternatif arayışların hız kazandığı bir dönemde tarımsal potansiyelleri yüksek ülkelerde biyoyakıtlar (biyodizel, biyogaz ve biyoetanol) yeni firsat açılımları oluşturmuştur. Güneş, rüzgar, hidrolik enerji, jeotermal enerji ve hidrojen enerjisi gibi yenilenebilir enerji kaynaklarından olan biyokütle enerjisi büyük bir potansiyele sahiptir (URL 2, 2013).

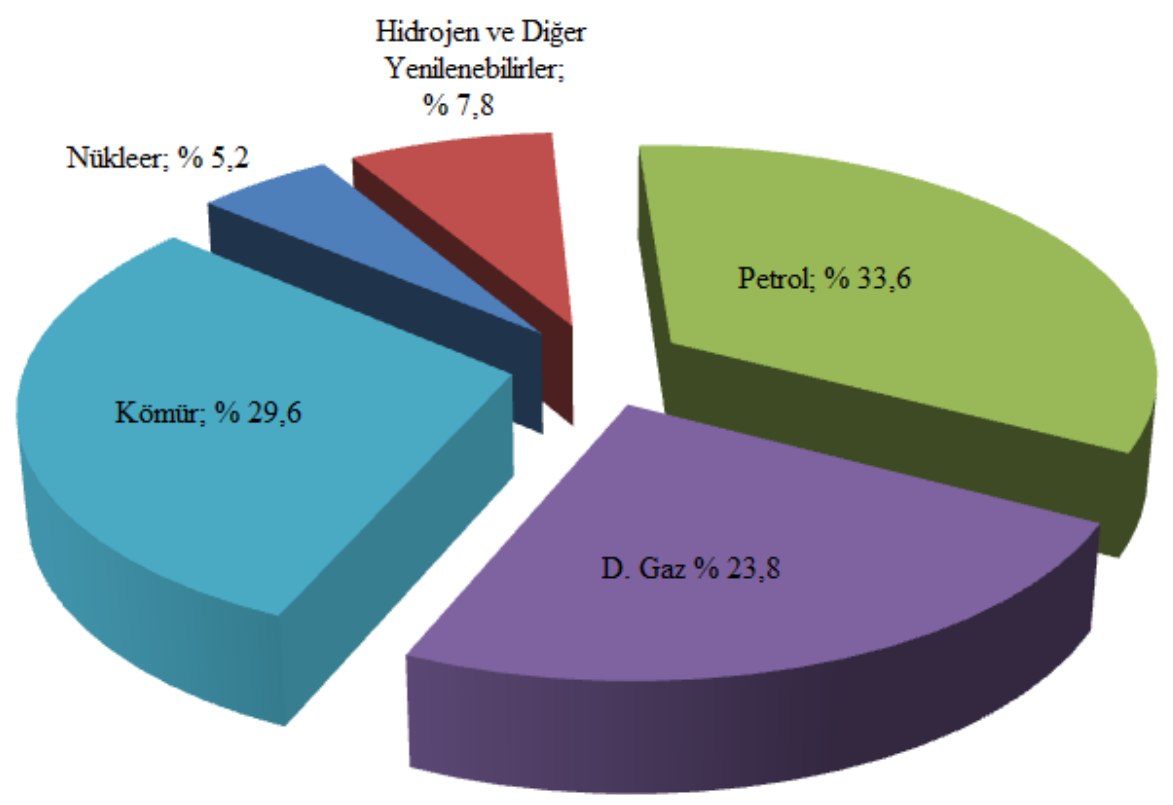

Şekil 2. Dünya'da primer enerjilerin kullanım payları (Türkyılmaz ve Özgiresun, 2012)

Şekil 2'de görüldüğü üzere, dünyadaki primer enerji kullanım payı en fazla petrol ve petrol türevlerinde \% 33,6'dır. Petrolü sırası kömür \% 29,6, doğal gaz \% 23,8, hidrojen ve diğer yenilenebilirler $\%$ 7,8 ve nükleer enerji $\% 5,2$ oranında takip etmektedir.

Geçtiğimiz 25 y1lı aşkın bir sürede dünya enerji talebi ortalama olarak y1lda \% 2 artmıştır. Dünya birincil enerji tüketimi miktarı 12.000 milyar ton eşdeğer petrol (TEP)'dir. 2030 yılında dünya primer enerji arzının 16.500 milyar TEP'e ulaşılacağ tahmin edilmektedir. En az primer enerji kullanım payı nükleer enerji kaynaklarına aittir (Türkyılmaz ve Özgiresun, 2012).

Şekil 3'de görüldüğü üzere, dünyada petrol'ün \% 30'u Ortadoğu'da, doğalgaz'ın \% 33'ü Avrupa ve Avrasya'da, kömür'ün \% 67'si Asya Pasifik'te, nükleer enerjinin \% 44'ü Avrupa ve Avrasya'da, hidroelektriğin $\%$ 32'si Asya Pasifik'te ve yenilenebilir enerjinin ise \% 44'ü Avrupa ve Avrasya'da üretilmektedir. 


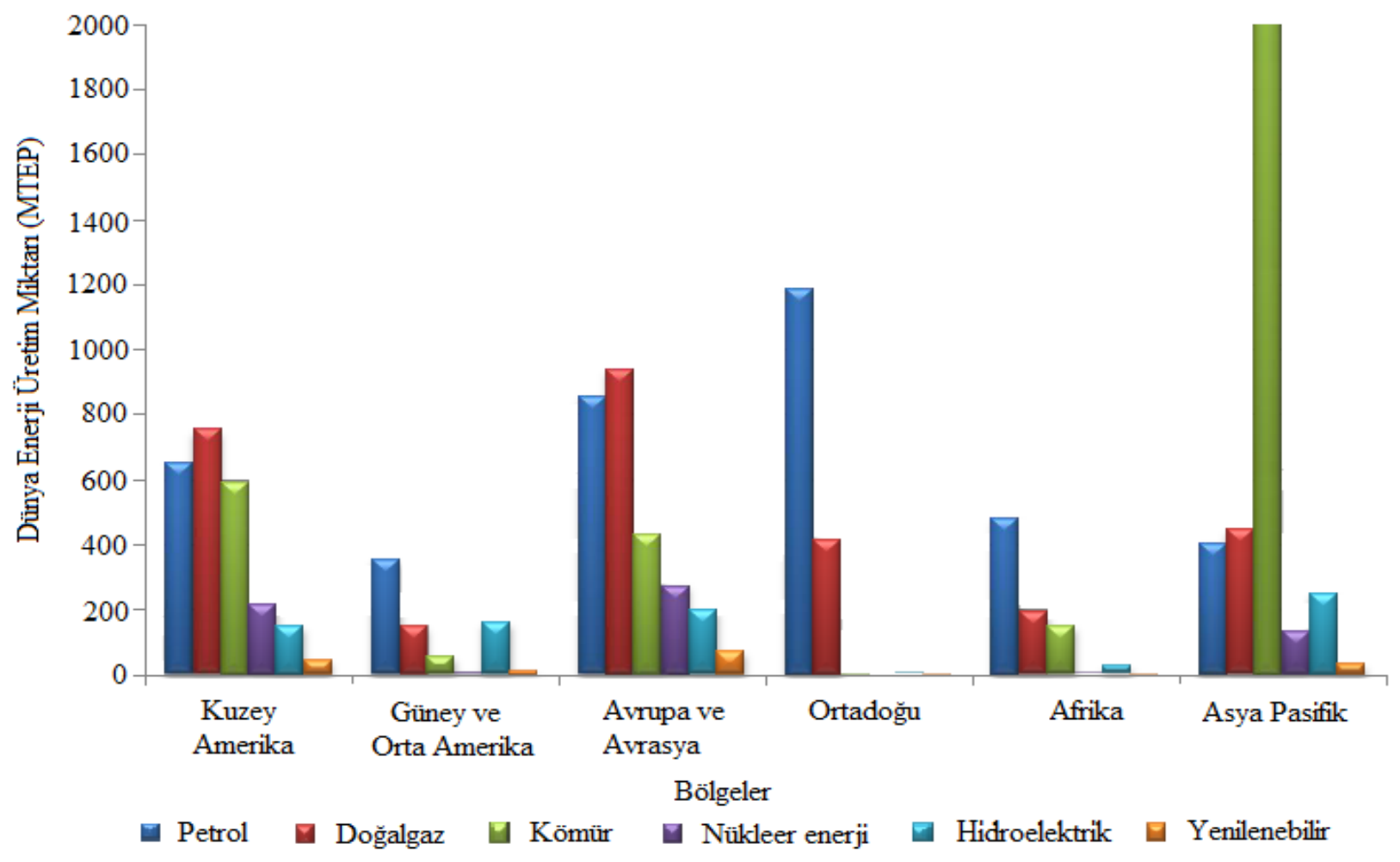

Şekil 3. 2010 yılı bölgelere göre dünya enerji üretimi Milyon TEP (URL 3, 2013)

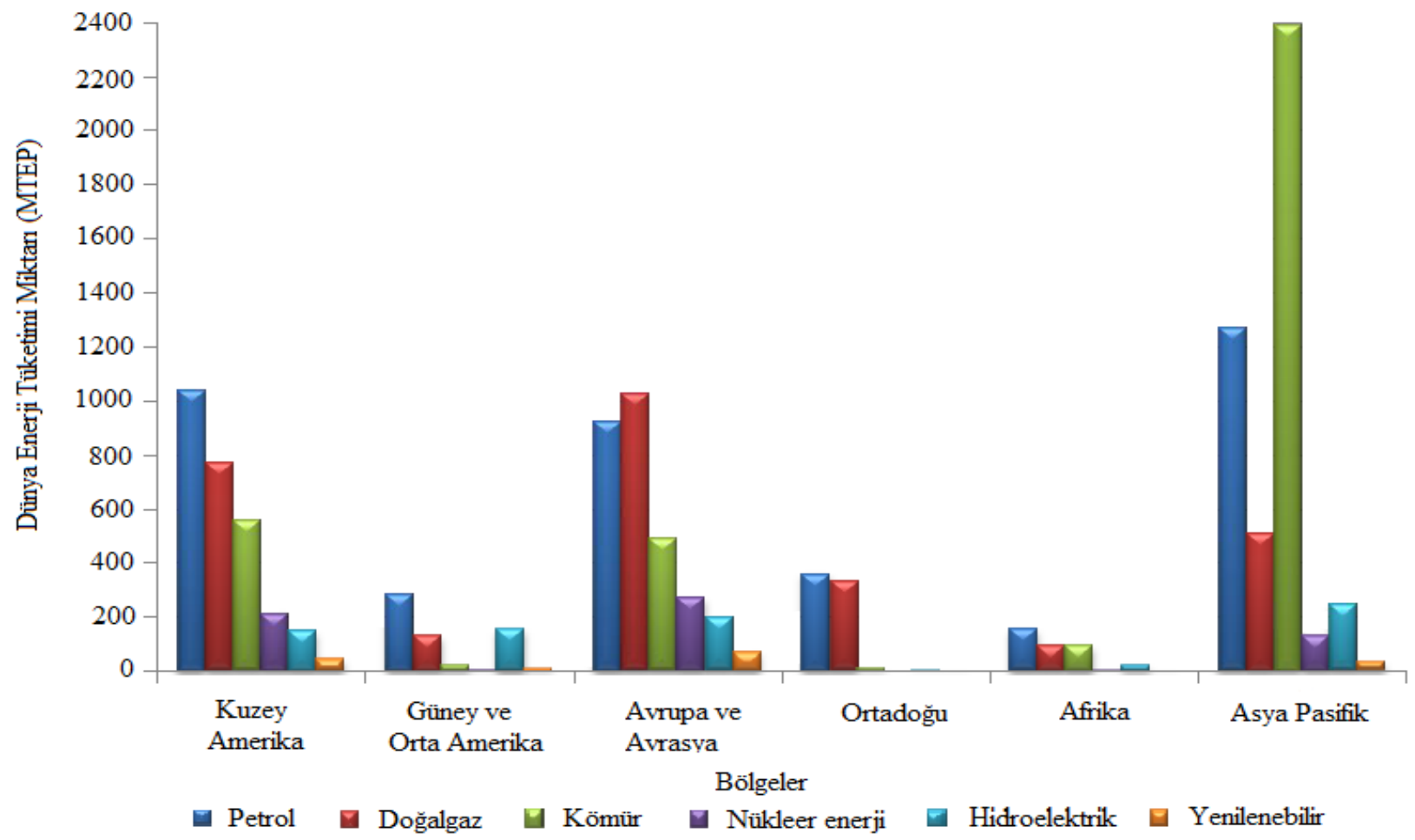

Şekil 4. 2010 yılı bölgelere göre dünya enerji tüketimi Milyon TEP (URL 3, 2013) 
Şekil 4'de görüldüğü gibi, dünyada petrolün $\%$ 31'i Asya Pasifik'te, doğalgaz'in \% 36's1 Avrupa ve Avrasya'da, kömür'ün \% 67'si Asya Pasifik'te, nükleer enerjinin \% 44'ü Avrupa ve Avrasya'da, hidroelektriğin \% 32'si Asya Pasifik'te ve yenilenebilir enerjinin ise \% 44'ü Avrupa ve Avrasya'da tüketilmektedir (URL 3, 2013).

2010 verilerine göre Tablo 1'de ülkelerin, enerji kaynağına göre yenilenebilir enerjide kurulu güç alanındaki sıralamaları verilmiştir. $\mathrm{Bu}$ siralamaya göre dünyada yenilenebilir enerji alanında kurulu güç bakımından ilk iki sırayı Çin ve ABD almaktadır. Hangisinin birinci olduğunu hidroelektrik gücü belirlemektedir. Hidroelektriği dahil ederek yapılan sıralamada Çin birinci gelirken, ABD ikinci sırada yer almaktadır. $\mathrm{Bu}$ ülkeleri sirasıyla; Kanada ve Brezilya izlerken hemen ardından birbirine yakın seviyedeki ülkeler olarak Almanya ve Hindistan gelmektedir. Hidroelektrik hariç tutulduğunda ise; ABD, Çin, Almanya, İspanya ve Hindistan olarak siralanmaktadır. Yenilenebilir enerji kaynaklarının tipine göre siralamaya baktığımızda; Çin, rüzgâr ve hidroelektrikte ilk siradayken, ABD jeotermal ve biyoenerjiyle elektrik üretiminde birincidir. Güneş panelleriyle (PV) elektrik üretiminde Almanya, yoğunlaştırılmış güneş enerjisi (CSP) ile elektrik üretiminde ise İspanya dünyada lider konumdadır (Anonim, 2011a).

Tablo 1. 2010 ülkelerin, enerji kaynağına göre yenilenebilir enerjide kurulu güç alanındaki sıralamaları (Anonim, 2011a)

\begin{tabular}{|c|c|c|c|c|c|c|}
\hline Sira No & $\begin{array}{c}\text { Toplam } \\
\text { (Hidrosantral } \\
\text { dahil) }\end{array}$ & $\begin{array}{c}\text { Toplam } \\
\text { (Hidrosantral } \\
\text { hariç) }\end{array}$ & Rüzgar & Biyokütle & Jeotermal & Güneş \\
\hline 1 & Çin & $\mathrm{ABD}$ & Çin & $\mathrm{ABD}$ & $\mathrm{ABD}$ & Almanya \\
\hline 2 & $\mathrm{ABD}$ & Çin & $\mathrm{ABD}$ & Brezilya & Filipinler & İspanya \\
\hline 3 & Kanada & Almanya & Almanya & Almanya & Endoznezya & Japonya \\
\hline 4 & Brezilya & İspanya & İspanya & Çin & Meksika & İtalya \\
\hline 5 & Hindistan & Hindistan & Hindistan & İsveç & İtalya & $\mathrm{ABD}$ \\
\hline
\end{tabular}

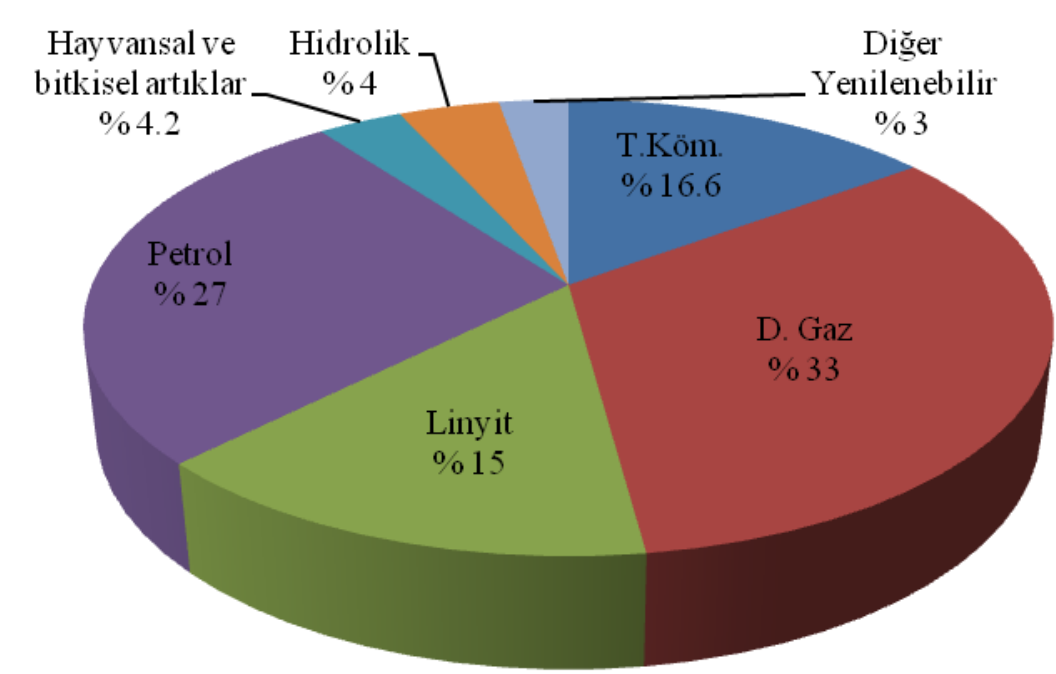

Şekil 5. Türkiye'de primer enerjilerin kullanım payları (Türkyılmaz ve Özgiresun, 2012) 
Şekil 5'de ifade edildiği üzere, enerji arzında ilk sırayı \% 33'lik pay ile doğalgaz alırken, bunu sirasiyla \% 27'lik pay ile petrol, \% $16,6^{\prime}$ lık pay ile kömür, $\%$ 15'lik pay ile linyit ve \% 11,2'lik pay ile hidrolik dâhil olmak üzere yenilenebilir enerji kaynakları izlemiştir.

Türkiye 109,3 milyon TEP enerji tüketimi ile dünyadaki enerji tüketimi en yüksek 22 . ülkesidir. 2010 yılı Türkiye toplam birincil enerji tüketim miktarı 109.266 KTEP ve tüketimin $\% \quad 89,3$ 'ü fosil yakıtlardır. Türkiye'nin yıllık enerji talep artış miktarı 1990'dan itibaren \% 4,6'dır. AB'nin aynı dönemdeki yıllık talep artış oranı ise \% 1,6'dır (Türkyılmaz ve Özgiresun, 2012). Ülkemizde enerji tüketiminin üretimi aşmasından ötürü Türkiye önemli bir enerji ithalatçısı konumundadır.

Yenilenebilir enerji kaynakları içinde yer alan organik atıklar ve enerji bitkilerinden elde edilen biyogaz günümüzde pek çok gelişmiş ülkenin enerji portföyünde geniş yer bulmaktadır. Almanya'da 4078 biyogaz tesisinden elde edilen 12 milyar kWh elektrik 3,5 milyon ev'in enerji ihtiyacinı karşılamaktadır. 11.000 kişinin istihdam edildiği sektörde 2020 yılında tüketilen elektriğin \% 20'sinin yaklaşık 85 milyar kWh'inin biyogazdan karşılanması hedeflenmektedir. Avrupa Birliği'nde, biyogazın ulaştırma yakıtı olarak kullanımı giderek yaygınlaşmaktadır (Anonim, 2011b).

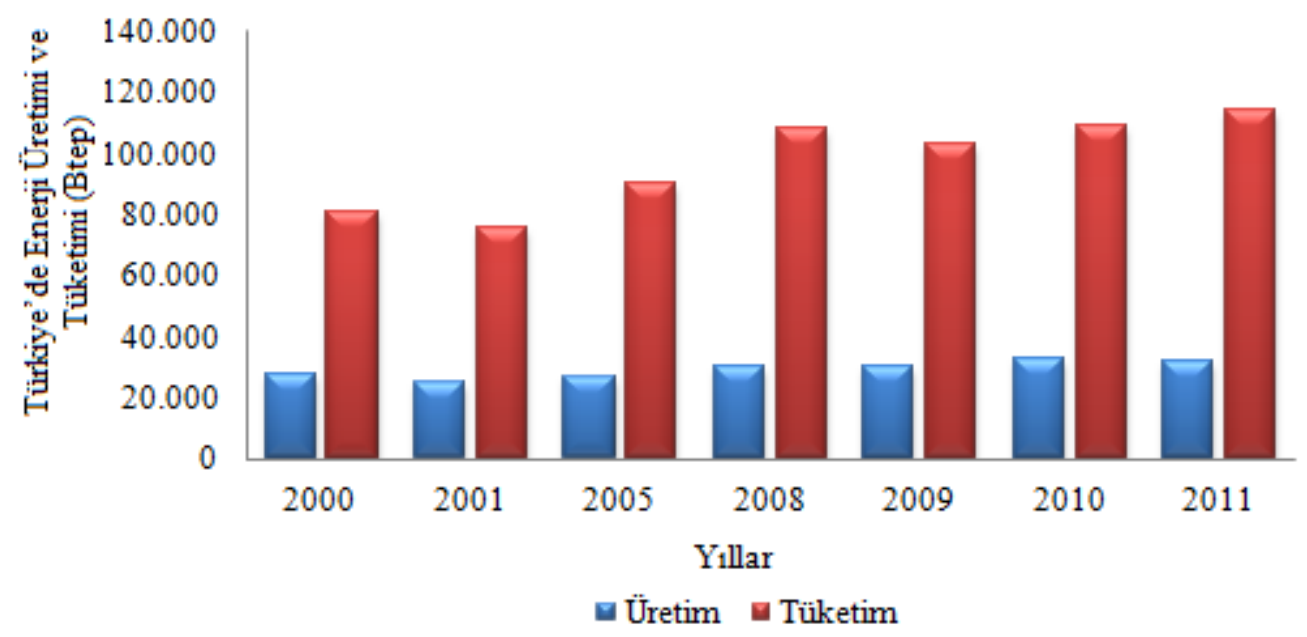

Şekil 6. Türkiye'de yerli kaynaklardan enerji üretimi ve toplam enerji tüketimi (ETKB, 2012).

2000-2011 y1lları arasında Türkiye'de yerli kaynaklardan enerji üretim ve toplam enerji tüketim miktarları Şekil 6'da görüldüğü gibidir. Şekilden de görüldüğü gibi, ülkemizde enerji üretimi yıllar arasında çok fazla değişmemekte, fakat yıllar arttıkça enerji tüketimi miktarı artmaktadır. Türkiye'de yerli kaynaklardan enerji üretiminin enerji tüketimini karşılama oranı yıllar içerisinde hızla azalmıştır. Bu oran 2000 yılında \% 48,1 iken, 2011 yılında \% 28,2 olarak gerçekleşmiştir (ETKB, 2012).

\section{Biyodizel}

Çevre dostu, yenilenebilir hammaddelerden elde edilebilen, atık bitkisel ve hayvansal yağlardan üretilebilen, anti-toksik etkili biyolojik olarak hızlı ve kolay bozunabilen kanserojenik madde ve kükürt içermeyen, yüksek alevlenme noktası ile kolay depolanabilir, taşınabilir ve kullanılabilir, yağlayıcılık özelliği mükemmel, motor ömrünü uzatan, motor karakteristik değerlerinin iyileşmesini sağlayan, kara ve deniz taşımacılığında kullanabilen, isıtma 
sistemlerinde ve jeneratörlerde kullanıma uygun stratejik özelliklere sahip ve ticari başarıyı yakalamış bir yeşil yakıttır (URL 4, 2012).

Biyodizel petrol içermez; fakat saf olarak veya her oranda petrol kökenli dizelle karıştırılarak yakıt olarak kullanılabilir. Saf biyodizel ve dizel-biyodizel karışımları herhangi bir dizel motoruna, motor üzerinde herhangi bir modifikasyona gerek kalmadan veya küçük değişiklikler yapılarak kullanılabilir.

\subsection{Dünya'da Biyodizel Üretim Miktarı}

Şekil 7'de görüldüğg̈ gibi, biyodizel üretimi ülkelere göre harita üzerinde verilmiştir. $A B$, 2010 yllında dünya genelindeki toplam üretimin \% 53'üne denk gelen 10 milyar litrelik kapasitesiyle dünya biyodizel üretiminin merkezi haline gelmiştir. Biyodizel, Avrupa'da biyoyakıt tüketimini devasa boyutlara çıkarmıștır. Ancak, bölge genelindeki büyüme oranı 2009'daki \% 19 seviyesinden 2010'da \% 2'lere gerileyerek yavaşlamaya devam etmiştir. Kıta genelindeki birçok ülkede yaşanan bu düşüşler $\mathrm{AB}$ dışındaki ülkelerden (Kanada, Arjantin ve Endonezya dahil) sağlanan ucuz ithalattan kaynaklanmıştır. $\mathrm{Bu}$ trend, iç talebin daralmasına bağlı olarak birçok tesisin kapanmasina, ithalata uygulanan tarifelerde genişlemeye yol açmıştır. Biyodizel üretimi Belçika, Slovakya, İspanya ve İngiltere dahil birçok AB üyesi ülkelerde gerilemiştir. Biyodizel üretiminde Almanya, ABD, Fransa, Arjantin ve Brezilya dünyanın ilk beş ülkesi arasındadır. Almanya, 2,9 milyar litre ile 2010 yılında dünyanın en büyük biyodizel üreticisi olma konumunu sürdürmüştür.

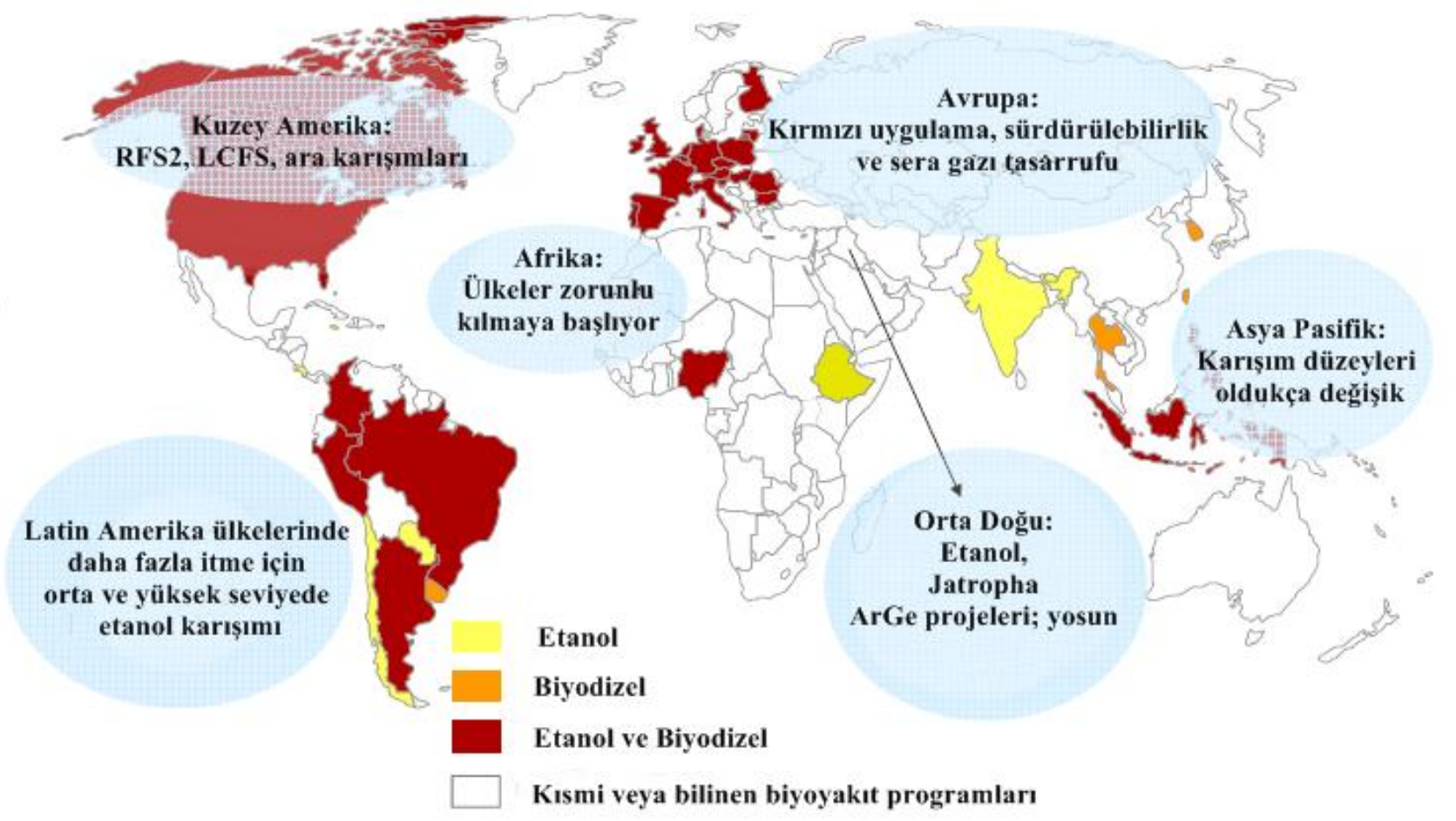

Şekil 7. Dünyada biyodizel üretimi (Hart Energy, 2012)

Şekil 8'de görüldüğü gibi, dünyada biyodizel üretimi yaklaşık olarak 2005 yılında 5 Mtep, 2014 yilında 30 Mtep ve 2021 yilında ise 42 Mtep olması beklenmektedir. Biyodizel ticareti ise, yıllar içinde pek fazla artış göstermemektedir. Avrupa'da biyodizel üretimi yaklaşık olarak, 2005 yılında 20 Mtep, 2014 y1lında 55 Mtep ve 2021 yilında ise 80 Mtep olması tahmin edilmektedir. Biyodizel'in toplam kullanımı Avrupa Birliği 
devletlerinin uyguladığı teşviklerle birlikte her geçen y1l daha fazla arttı̆g 1 görülmektedir (FAO, 2013).
Şekil 9'da gösterildiği gibi, en fazla üretim ve tüketim payına sahip olan ülke ABD iken, en az üretim payına sahip olan ülke Tayland ve en az tüketim payına sahip olan ülke ise Tayland olduğu görülmektedir.

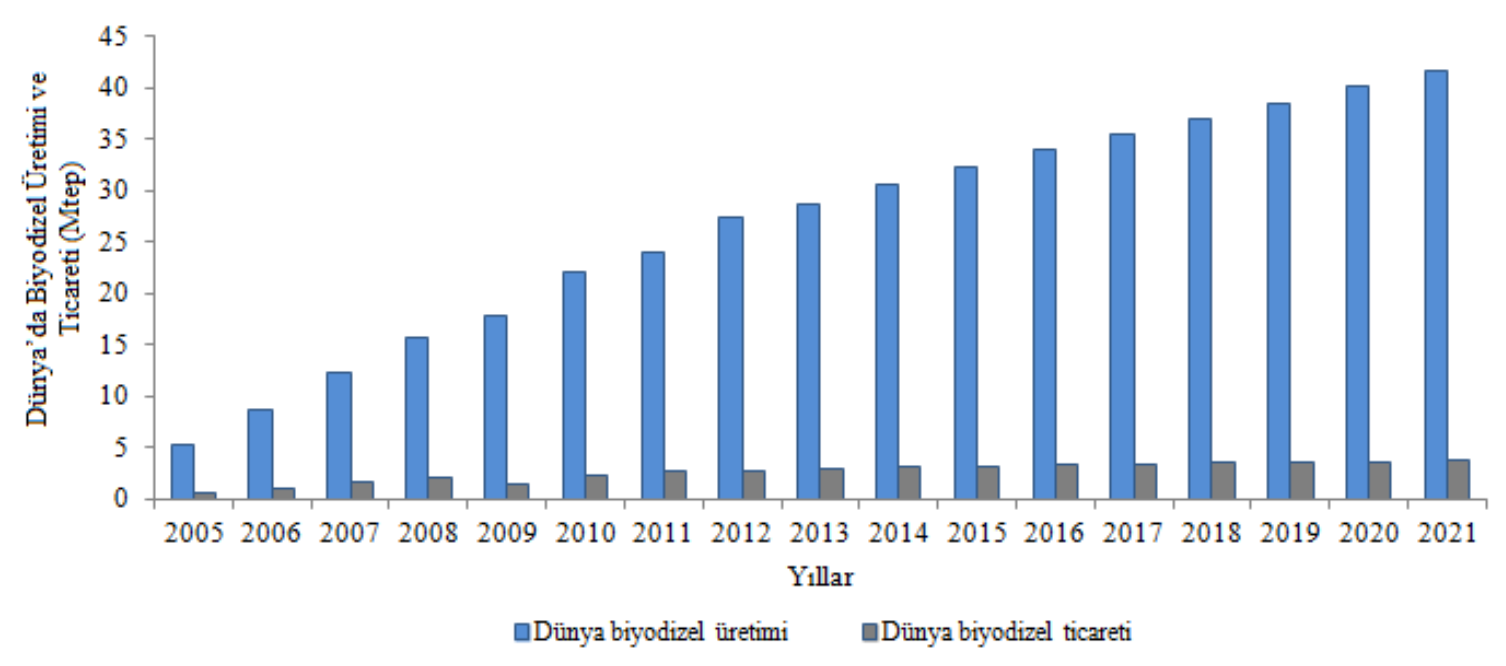

Şekil 8. Dünya biyodizel pazarının gelişimi (FAO, 2012)
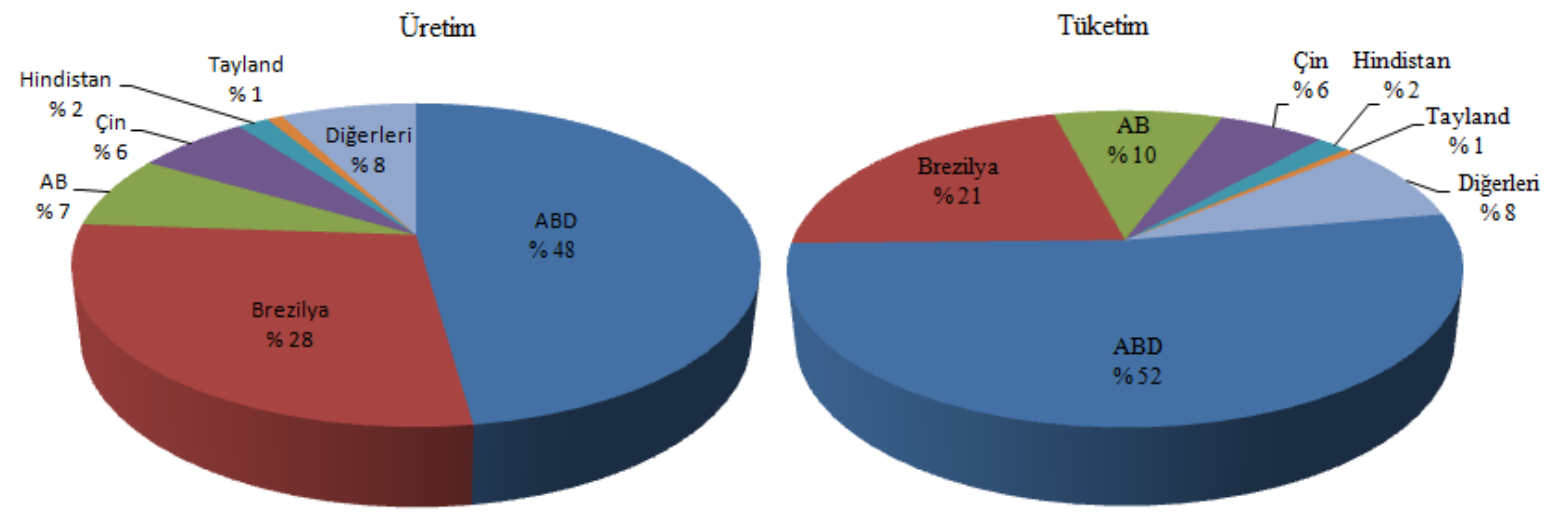

Şekil 9. Bazı ülkelerde biyodizel üretimi ve tüketimi (FAO, 2013)

\subsection{Türkiye'de Biyodizel Üretim Miktarı}

Şekil 10'da, Türkiye'de tarıma elverişli olduğu halde kullanılmayan alanlarda bölgelere göre biyodizel üretim potansiyeli verilmektedir. $\mathrm{Bu}$ potansiyel toplamda en düşük 9. bölge'de 47.000-71.000 ton ve en yüksek ise 2 . bölge'de 186.000-308.000 ton olduğu görülmektedir.

Şekil 11'de görüldüğü üzere, Türkiye'de biyodizel üretimi yapan iller verilmiştir.
Şekilden de anlaşılacağı üzere, Ankara ve Gaziantep'te 21'in üzerinde biyodizel üretimi yapan firma sayıs1 mevcuttur. $\mathrm{Bu}$ illerimizi sirasiyla, İzmir ve Adana'da 16-20 firma say1s1, İstanbul ve Kocaeli'nde 11-15 firma sayıs1, Balıkesir, Bursa, Afyon, Konya, Mersin, Hatay, Şanlıurfa, Diyarbakır'da 6-10 firma sayısı ve kalan işaretli illerimizde ise 15 firma sayısı takip etmektedir. 


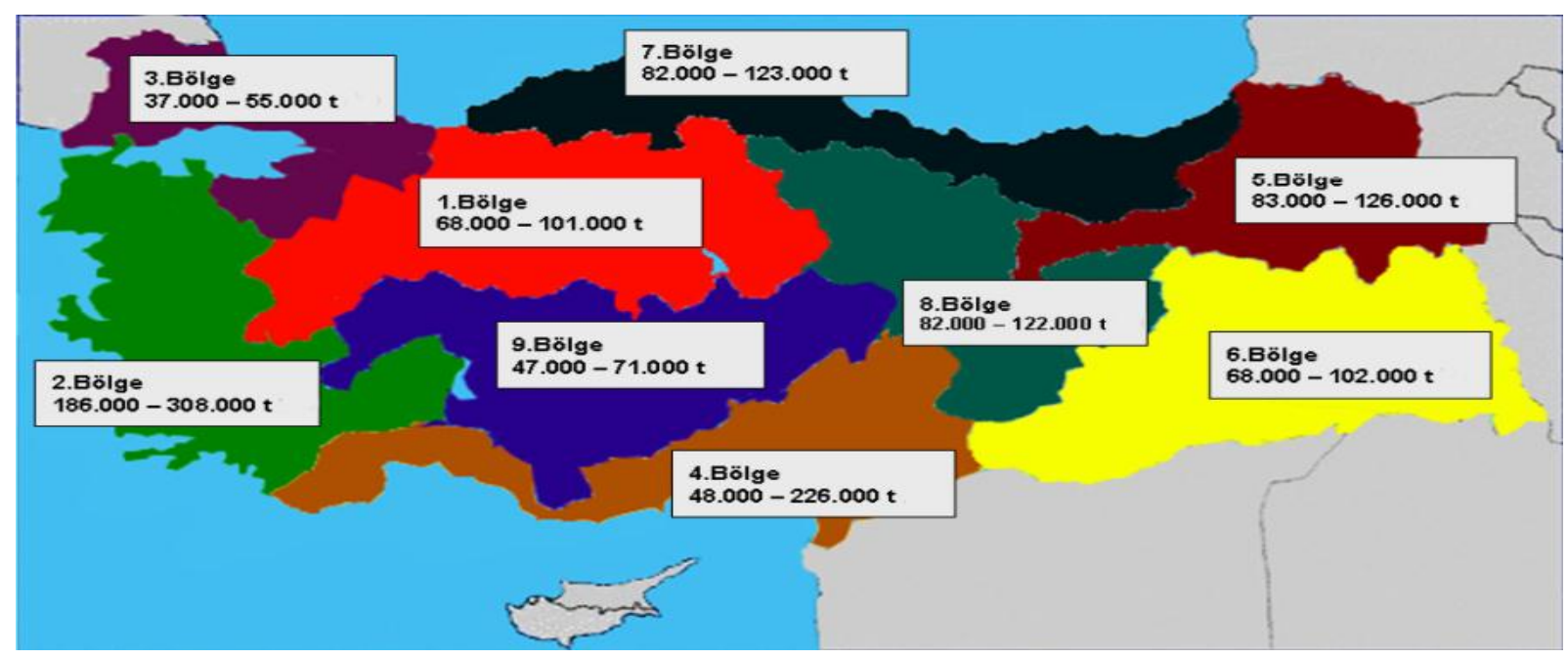

Şekil 10. Türkiye'de kullanılmayan alanlarda biyodizel üretim potansiyeli (URL 5, 2013)

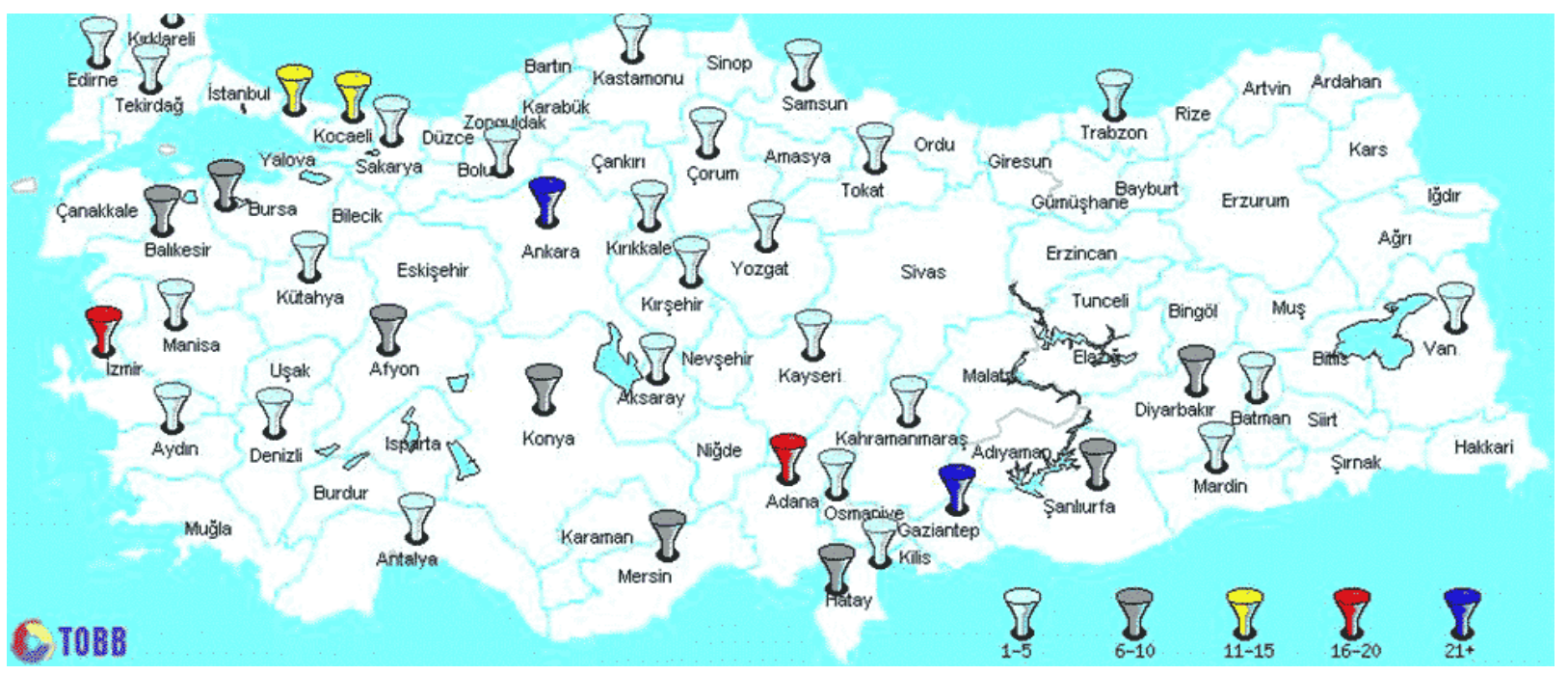

Şekil 11. Türkiye'de biyodizel üretiminin mevcut durumu (URL 6, 2013)

Ülkemizdeki biyodizel; 14 Eylül 2011 verilerine göre Enerji Piyasası Düzenleme Kuruluna (EPDK) kayitlı 36 firmanın biyodizel üretim lisansina sahip olduğu tespit edilmiştir. Ancak yerli tarım ürünlerinden aktif biyodizel üretimi yapan sadece bir firma bulunmaktadır. İzmir'de faaliyet gösteren bu firma Eskişehir'den Turhal'a, Uşak'tan Siirt'e kadar verimsiz tarım arazilerinde yetiştirilen aspir bitkisi ile biyodizel üretimini gerçekleştirmektedir. Tesis kapasitesi 20 bin ton/yıl'dır. Çevre Bakanlığı verilerinde üç adet tesis atık yağdan biyodizel üretimi için izinli görünse de bunlardan sadece bir tanesi EPDK'dan lisanslıdır ve aktif üretim yapmaktadır. Ülkemizde yerli ham maddeyle üretilen biyodizelin motorinle harmanlanan \% 2'lik dilimi Özel Tüketim Vergisi (ÖTV)'den muaf tutulmaktadır. 27.09.2011 tarihli Resmi Gazete'de yayımlanarak yürürlüğe giren EPDK Kararı gereğince piyasaya akaryakıt olarak arz edilen motorin türlerinin, yerli tarım ürünlerinden üretilmiş biyodizel içeriğinin 1 Ocak 2014 tarihi itibarıyla en az $\%$ 1, 1 Ocak 2015 tarihi itibarıla en az \% 2 ve 1 Ocak 2016 tarihi itibarıla en az \% 3 olması zorunluluğu getirilmiştir (URL 6, 2013). Kurulan biyodizel tesislerinin toplam kapasiteleri 1,5 milyon ton civarında olmakla birlikte, yerli hammadde bulunmaması 
nedeniyle pek çok tesisin kapandığı bilinmektedir.

\subsection{Biyodizel Üretimi}

Biyodizel üretiminde bitkisel yağ olarak kolza, ayçiçeği, soya ve kullanılmış kızartma yağları, alkol olarak metanol ve katalizör olarak alkali katalizörler (sodyum veya potasyum hidroksit) tercih edilmektedir. Haysansal yağlar da biyodizel üretiminde kullanılabilir.

Yağların yakıt olarak kullanılması için ilk olarak viskozitelerini düşürecek işlemlere tabi tutulması gerekmektedir. Yağların viskozitesi 1s1l ve kimyasal yöntem uygulanarak azaltılabilir. Isıl yöntemde, ön 1sitma ile yağların viskozitesinin düşürülmesi amaçlanmaktadır. Isıl yöntemin hareketli bir araç motorunda uygulaması sırasında oluşabilecek problemler nedeniyle kimyasal yöntem daha çok kullanılmaktadır (Ulusoy, 1999).

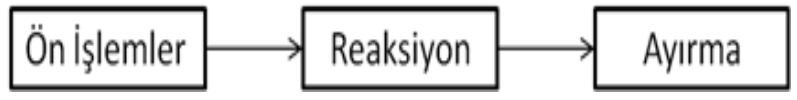

Şekil 12. Biyodizel üretim aşamaları

Şekil 12'de biyodizel üretim aşamaları ve Şekil 13'te ise biyodizel üretimi şematik olarak verilmiştir. Biyodizel üretim teknolojisinde zorluk bulunmamaktadir. Üretimdeki en önemli nokta biyodizelin saflık derecesidir. $\mathrm{Bu}$ nedenle rafinasyon aşaması önem kazanmaktadır. Biyodizel \% 99 değeri üzerinde saf üretilmelidir (Oğuz vd., 2004).

Biyodizelin diğer yakıtlara alternatif olabilmesinin şartı, kalite değerlerinin petrodizel ile rekabet edebilir olmasıdır. İyi bir üretim projesi ile biyodizel, petrodizele yakın değerler göstermektedir. Biyodizelin fiziksel özellikleri Tablo 2'de verilmiştir.

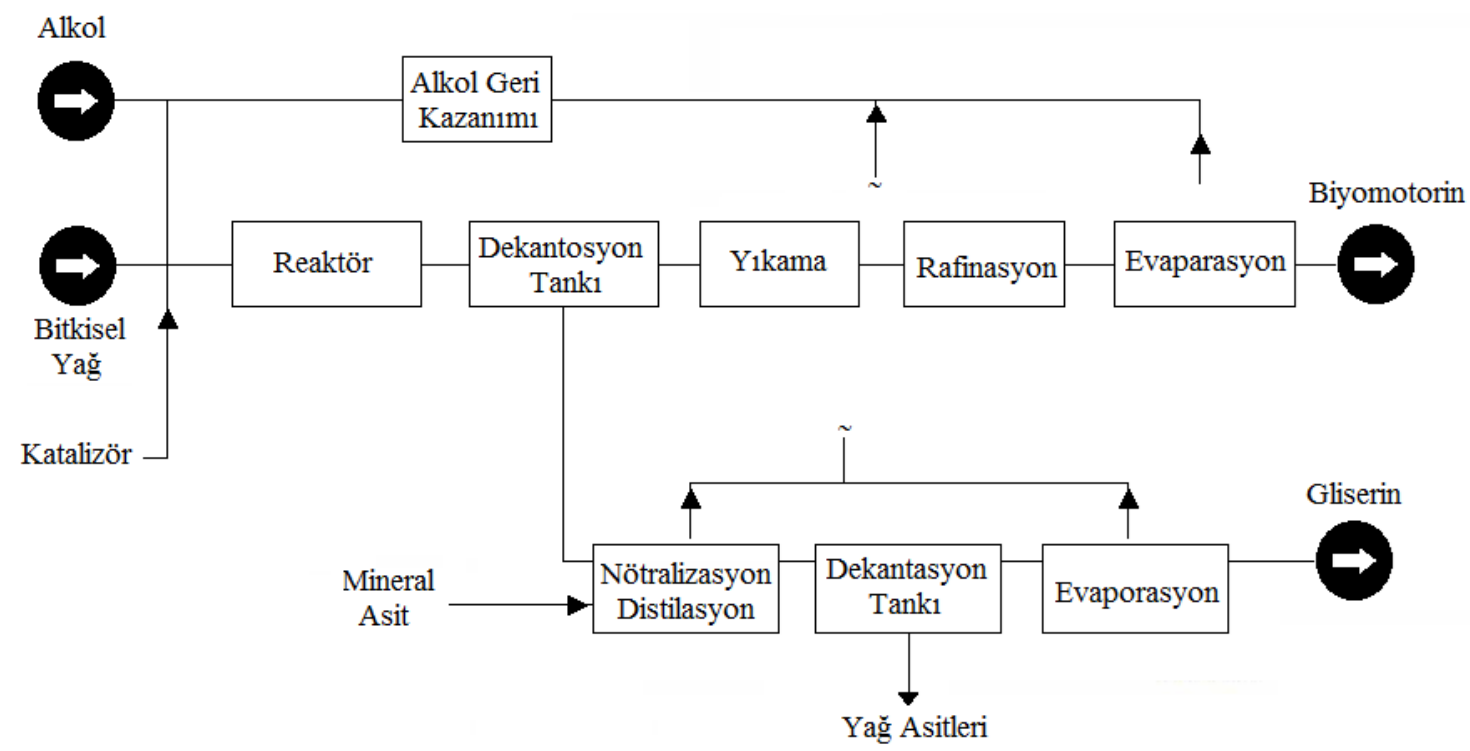

Şekil 13. Biyodizel üretimi (Güler, 2008)

Biyodizel üretiminde dört yöntem mevcuttur. Bunlar; seyreltme, mikroemüsyon oluşturma, piroliz ve transesterifikasyon'dur. Günümüzde en yaygın olarak kullanılan yöntem ise transesterifikasyon (alkoliz) yöntemidir. Tablo 3'de biyodizel üretim yöntemlerinin karşılaştırılması verilmiştir (URL 8, 2011).
Biyodizel, tarımsal bitkilerden elde edilmesi nedeniyle, biyolojik karbon döngüsü içinde, fotosentez ile $\mathrm{CO}_{2}{ }^{\prime} \mathrm{i}$ dönüştürüp karbon döngüsünü hızlandırdığı için sera etkisini artırıc1 yönde etki göstermez. Diğer bir deyişle, biyodizel $\mathrm{CO}_{2}$ emisyonu için doğal bir yutak olarak düşünülebilir. Ayrıca CO, $\mathrm{SO}_{\mathrm{x}}$ emisyonlarının, partikül madde ve 
yanmamış hidrokarbonların daha az salındığ 1 kanıtlanmıștır.

B5: $\% 5$ biyodizel $+\% 95$ dizel

B20: \% 20 biyodizel $+\% 80$ dizel
B50: \% 50 biyodizel + \% 50 dizel

B100: \% 100 biyodizeldir (Sabanc1 vd., 2010).

B100 ve B20 oranında biyodizel kullanılması durumunda ortaya çıkabilecek emisyon değerleri Tablo 4'de verilmiştir.

Tablo 2. Biyodizelin fiziksel özelikleri (URL 7, 2013)

\begin{tabular}{ll}
\hline Biyodizelin Fiziksel Özellikleri & \\
\hline Özgül ağırlı & 0,88 \\
$40{ }^{\circ} \mathrm{C}$ 'de kinematik viskozite & $4,0-6,0$ \\
Setan sayısı & $48-65$ \\
Yüksek 1sıl değeri, Btu / gal & 127.042 \\
Alt 1s1l değeri, Btu / gal & 118.170 \\
$15,5{ }^{\circ} \mathrm{C}$ 'de yoğunluk, lb / gal & 7,3 \\
Karbon, wt \% & 77 \\
Hidrojen, wt \% & 12 \\
Oksijen,.wt $\%$ & 11 \\
Kaynama noktas1, ${ }^{\circ} \mathrm{C}$ & $315-350$ \\
Parlama noktas1, ${ }^{\circ} \mathrm{C}$ & $100-170$ \\
Kükürt, wt $\%$ & $0,0-0,0024$ \\
Bulut noktası, ${ }^{\circ} \mathrm{C}$ & -3 ile 15 \\
Akma noktas1, ${ }^{\circ} \mathrm{C}$ & -5 ile 10 \\
\hline
\end{tabular}

Tablo 3. Biyodizel üretim teknolojilerinin karşılaştırılması (Aksoy, 2010)

\begin{tabular}{|c|c|c|}
\hline Teknolojileri & Avantaj & Dezavantaj \\
\hline Seyreltme & $\begin{array}{l}\text { Yenilenebilir, kullanıma } \\
\text { hazır, portatif, doğal sıvı }\end{array}$ & $\begin{array}{l}\text { Yüksek vizkozite, düşük } \\
\text { uçuculuk, doymamış hidrokarbon } \\
\text { zincirlerin reaktifliği }\end{array}$ \\
\hline Piroliz & $\begin{array}{l}\text { Basit işlem, petrol türevi } \\
\text { yakıtlar, benzin ve dizele } \\
\text { kimyasal benzerlik }\end{array}$ & $\begin{array}{l}\text { Yüksek enerjiden dolayı maliyet } \\
\text { yüksek }\end{array}$ \\
\hline Transesterifikasyon & $\begin{array}{l}\text { Yakıt özellikleri dizele daha } \\
\text { yakın, yüksek dönüşüm } \\
\text { verimliliği, düşük maliyetli, } \\
\text { bu yöntem sanayileşmiş } \\
\text { üretim için uygundur }\end{array}$ & $\begin{array}{l}\text { Düşük serbest yağ asidi ve su (baz } \\
\text { katalizatörü) gerekmektedir, } \\
\text { ürünleri nötralize ve yıkanmalıdır. } \\
\text { Çünkü üründen gliserol ve suyun } \\
\text { ayrılması güç olmaktadır. }\end{array}$ \\
\hline Mikroemüsyon oluşturma & $\begin{array}{l}\text { Herhangi bir katalizör, kısa } \\
\text { reaksiyon zamanı, yüksek } \\
\text { dönüşüm, iyi uyum }\end{array}$ & $\begin{array}{l}\text { düşük setan sayısı, düşük enerji } \\
\text { içeriği }\end{array}$ \\
\hline
\end{tabular}


Tablo 4. B100 ve B20 oranında biyodizel kullanılmasında ortaya çıkabilecek emisyon değerlerinin dizel yakıtlarla karşılaştırılması EPA ( Environmental Pollution Agency) (URL 8, 2011)

\begin{tabular}{lll}
\hline Emisyonlar & B20 $(\%)$ & B100 (\%) \\
\hline Yanmamış Toplam Hidrokarbonlar & -20 & -67 \\
Karbonmonoksit $(\mathrm{CO})$ & -12 & -48 \\
Partikül Madde (PM) & -12 & -47 \\
Sülfatlar & -20 & -100 \\
PAH (Polisiklik Aromatik Hidrokarbon) & -13 & -80 \\
Npah (Nitratlı PAH'lar) & -50 & -90 \\
Hidrokarbonların Ozon Tabakasına Etkisi & -10 & -50 \\
Hidroflorik Asit (HF) & $-2,10$ & $-15,51$ \\
Kükürt Oksitler $\left(\mathrm{SO}_{\mathrm{x}}\right)$ & $-1,61$ & $-8,57$ \\
Metan $\left(\mathrm{CH}_{4}\right)$ & $-0,51$ & $-2,7$ \\
Azot Oksitler $\left(\mathrm{NO}_{\mathrm{x}}\right)$ & $+/-2$ & +10 \\
Hidroklorik Asit $(\mathrm{HCI})$ & 2,71 & 13,54 \\
\hline
\end{tabular}

\subsection{Biyodizelin Avantajları ve Dezavantajları}

\subsubsection{Avantajlart}

Biyodizelin fiziksel ve kimyasal özelliklerindeki avantajları, motorda yanma verimini artırır ve $\mathrm{CO}$ parçacık ve $\mathrm{SO}_{\mathrm{x}}$ emisyonlarında azalmalar sağlar. Biyodizeldizel karışımı ile karşılaştırıldığında biyodizelin kullanılması ile $\mathrm{CO}, \mathrm{PM}, \mathrm{HF}, \mathrm{SO}_{\mathrm{x}}$ ve $\mathrm{CH}_{4}$ emisyonlarında azalma, $\mathrm{NO}_{x}$, $\mathrm{HCI}$ ve HC emisyonlarında ise artma görülmektedir. Biyodizel, değişiklik yapılmamış herhangi bir dizel motorunda dizel yakıtı ile değişik oranlarda karıştırılarak kullanıldığı gibi, \% 100 oranında da kullanılabilmektedir (Artukoğlu, 2006).

Biyodizeli oluşturan $\mathrm{C}_{16}-\mathrm{C}_{18}$ metil esterleri kolayca ve hızla parçalanarak çözülür. Biyolojik olarak ayrışabilir ve zehirli değildir. Yapılan testlere göre, kanoladan elde edilmiş biyodizelin 21 günde \% 99,6'sının ayrıştı̆̆ görülmüştür. Biyodizel çevre dostudur, alternatif bir enerji kaynağıdır, yenilebilir karakterlidir ve yerel imkânlarla üretilebilir. Dizele mukayese edildiğinde $\mathrm{CO}_{2}$ 'nin atmosferde birikimine ve bunun sonucunda da sera etkisine neden olmaz. Çünkü biyodizelin yanması sonucu oluşan $\mathrm{CO}_{2}$ biyodizelin elde edildiği bitkiler tarafından kullanılır (Öğüt ve Oğuz, 2006).
Biyodizelin, petrol kökenli dizel yakıtına göre daha yüksek tutuşma derecesine $\left(>110^{\circ} \mathrm{C}\right)$ sahiptir. $\mathrm{Bu}$ yanmaya doğrudan etki etmemesine rağmen, biyodizelin depolanması ve taşınabilirliği açısından daha güvenli hale getirmektedir (Mutlu vd., 2006).

\subsubsection{Dezavantajları}

Dizelden daha yüksek akma noktasına sahiptir. Bitkisel yağların doğrudan dizel yakıtı olarak kullanımlarını olumsuz yönde etkileyen başlıca faktör yüksek viskoziteleridir. Modern dizel motorlarının enjeksiyon sistemleri viskozite değişimlerine karşı hassasiyet gösterirler. Yüksek viskozite yakıtının yanma odasındaki atomizasyonunu bozmakta, damlacık boyutundaki büyümeyle tam yanmayı önlemektedir. Tamamlanmayan yanma ise yanma odasinda birikmelere, enjektörlerde koklaşma ve tıkanmalara ayrıca yağlama yağına bulaşmaya neden olmakta ve yağlama yağında kalınlaşma ile jelleşme görülmektedir.

Bitkisel yağların yakıt olarak kullanımında bir diğer sorun içerdikleri doymamış yağlardan kaynaklanır. Doymamış yapıların yağlama yağına karışması ve bu ortamda polimirezasyonu, motoru tahrip edecek viskozite artışlarına neden olmaktadır (Öztürk, 2007). 
Biyodizel soğuk hava şartlarından dizele göre daha çabuk etkilenir. Soğuk havalarda dizelden daha yüksek bulutlanma noktasına sahiptir. Biyodizelin 1sıl değeri dizele göre düşüktür. $\mathrm{Bu}$ durum motordaki yanma sonucunda bir miktar güç düşmesine yol açar (Öğ̈̈t ve Oğuz, 2006). Havayla temas eden biyodizel, özellikle yüksek sıcaklıklarda hızla oksitlenmeye başlar. Bununla birlikte biyodizelin, parlama noktası daha yüksektir. $\mathrm{Bu}$ yanmaya doğrudan etki etmemesine rağmen, biyodizelin depolanması ve taşınabilirliği açısından daha güvenli hale getirmektedir (Koç, 2011).

Biyodizel, depolama, taşıma ve motor malzemelerinde doğal ve butil kauçukları parçalamaktadır ve uzun süre depolanamaz. Saf (B100) kullanım durumunda ise motor malzemelerinde özellikle yakıt donanımındaki hortum, bağlantı elemanı ve contaların uygun malzeme ile değiştirilmesi gerekir (Artukoğlu, 2006).

\subsection{Biyodizel Üretiminde Kullanılan Bazı Yă̆ Bitkilerinin Özellikleri ve Miktarı}

Dünyada toplam 108 milyon ton bitkisel yă üretilmekte olup, halen bunun 6 milyon tonu biyodizel üretiminde kullanılmaktadır. Esasen dünyada üretilen tüm bitkisel yağların tamamı biyodizele çevrilse dünya dizel yakıt ihtiyacının ancak \% 7 'sini karşılayabilmektedir.

Ülkeler bazında dünya yağlı tohum üretimi Şekil 14'te verilmiştir. Şekilden de görüldüğü gibi, dünya yağlı tohum üretiminde ilk sırayı $\% 20$ ile ABD almaktadır. ABD'yi sırası ile $\% 17$ ile Brezilya, \% 13 ile Çin, \% 12 ile Arjantin ve $\% \quad 8$ ile Hindistan takip etmektedir. Türkiye ise yağlı tohum üreten ülkeler arasındaki payı \% 0,5'dir. Düne kadar nüfus artışları ve iklim şartlarının belirlediği dünya bitkisel yağ üretiminde bundan böyle tek belirleyicinin biyodizel olduğu ifade edilmektedir (URL 6, 2011). Şekil 15'ten anlaşıldığı üzere, ülkemizde en fazla ekili alana sahip olan yağlı tohum bitkisi ayçiçeğidir. Onu sırası ile soya, kolza ve aspir takip etmektedir.

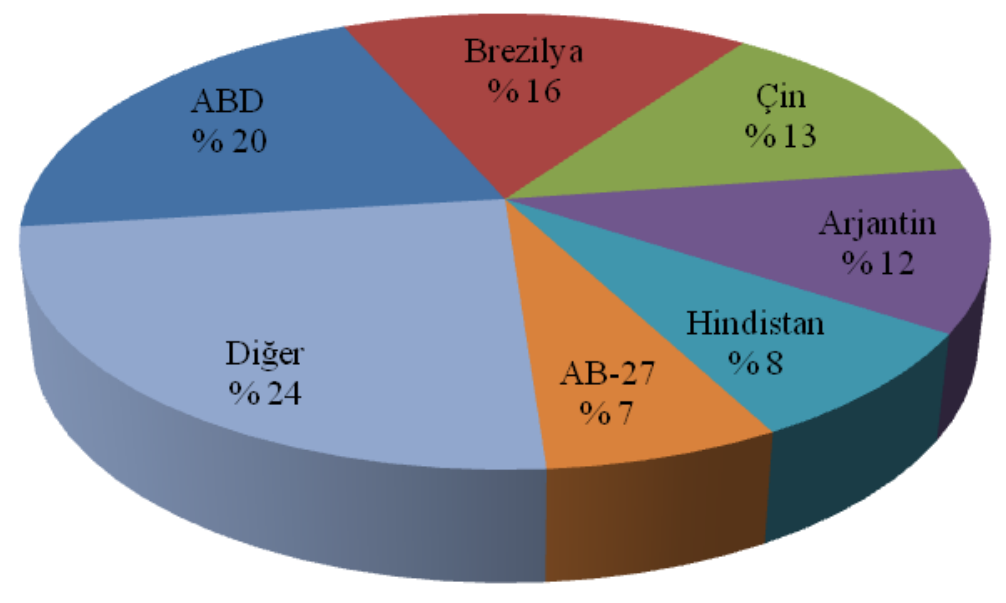

Şekil 14. 2011 yılı ülkeler bazında dünya'da yağlı tohum üretimleri (Uğur, 2012) 


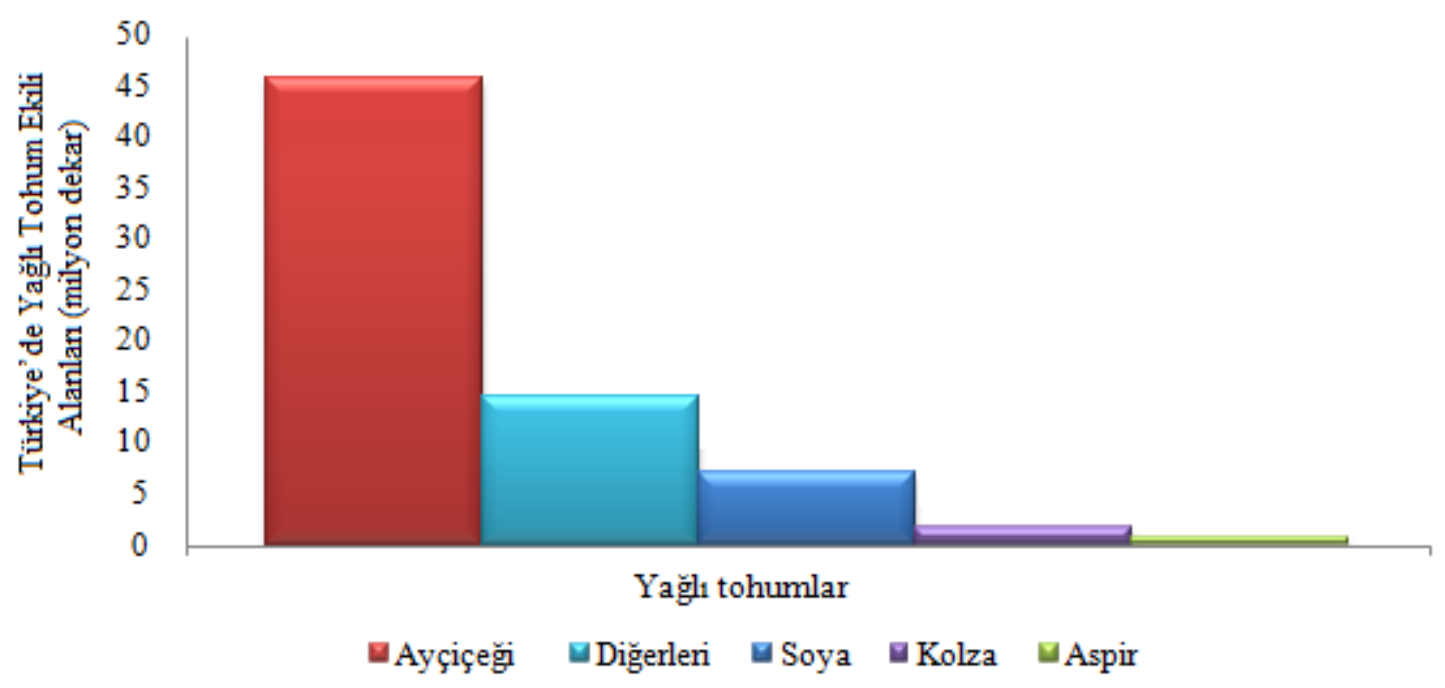

Şekil 15. Türkiye'de yağlı tohum ekim alanları (TÜİK, 2012)

Şekil 16'da, Türkiye'deki yağlı tohum üretim miktarları verilmiştir. 2007 yılında Türkiye'de yağlı tohum üretim miktarında düşüş olmasına rağmen sonraki yillarda üretim miktarları artmıştır. Üretimi en fazla yapılan yağlı tohum ayçiçeği ve en az yapılanı ise aspir bitkisidir. Ayrıca 2007 yılından sonra kolza ve soya üretimde hızlı bir artış gözlenmektedir.

Türkiye'de ekili alanların \% 6,2'sinde yağlı tohum bitki tarımı yapılmaktadır. Tarıma elverişli olup kullanılmayan alanlarda sulanabilir bölgelerde kanola ve sulanamayan bölgelerde aspir ekimi yapılmaktadır (İşler, 2012).

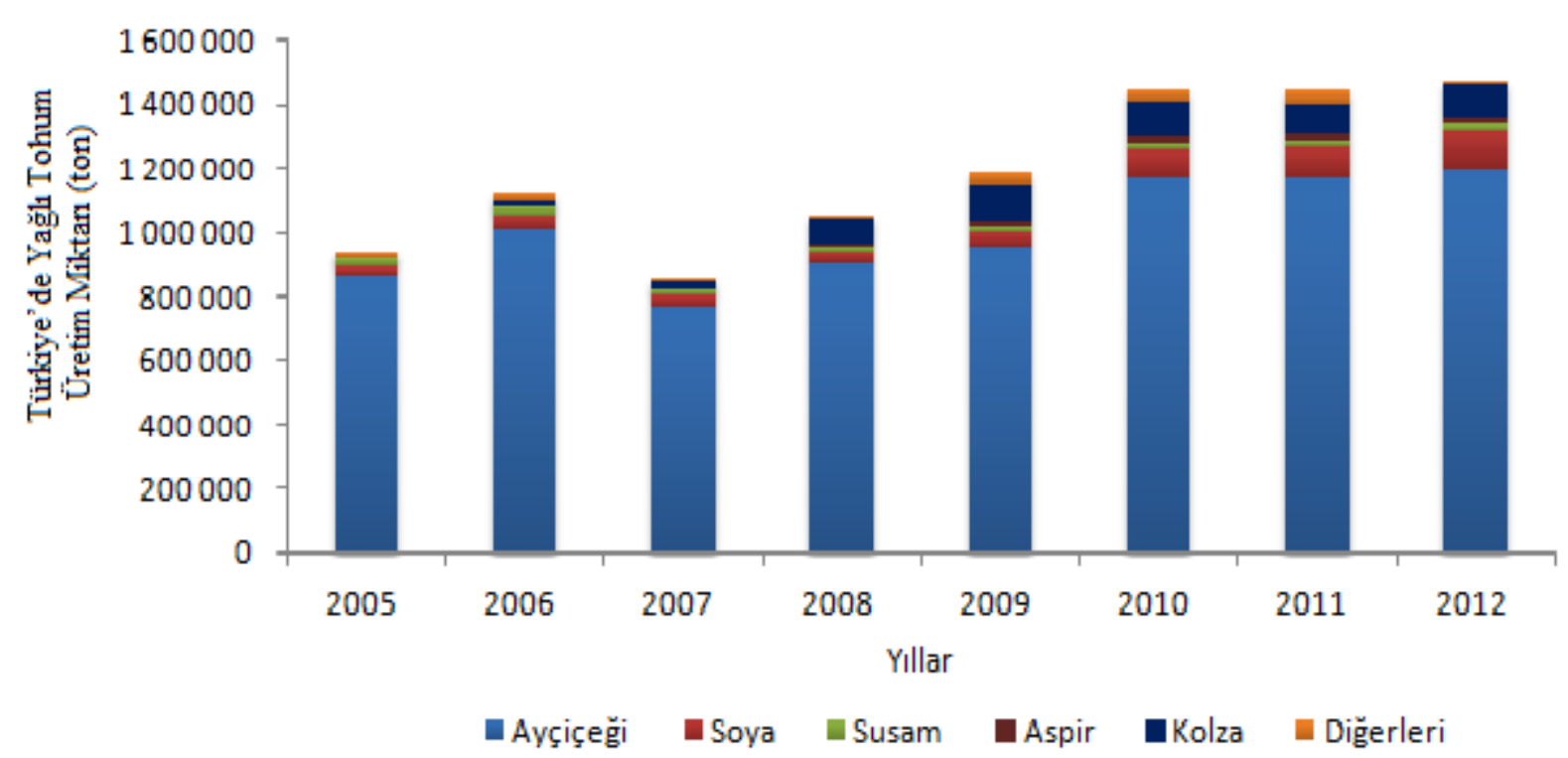

Şekil 16. Türkiye'de yağlı tohum üretim miktarları (TÜİK, 2012) 


\section{Sonuç ve Öneriler}

Dünyadaki enerji ihtiyacının karşılandığı fosil kökenli yakıtların azalmasıyla, yenilenebilir enerji kaynakları dikkat çekmektedir. Bu bağlamda biyodizel, yeni iş alanları açması dolayısıyla istihdam sağlanması, dünyanın hemen her yerinde üretilebilir oluşu, çevre ve canlı yaşam açısından risk oluşturmaması, atık maddelerin değerlendirilmesine imkan sağlaması gibi nedenlerden dolayı "üçüncü milenyumun yakıtı" olarak tanımlanmaktadır.

Biyodizel, özellikle taşımacılık sektörünün vazgeçilmezi olan dizel yakıtlarına alternatif bir yakıttır. Ekonomik katkısına ek olarak temiz bir yakıt olması, çevre açısından büyük önem arz etmektedir. Atık yağların biyodizele dönüştürülerek geri kazanımı, bu yağların çevreye verdiği zararı ortadan kaldırması ve biyodizelin dezavantajlarından biri olan yüksek maliyeti azaltması açısından oldukça önemlidir. Viskozitesi yüksek olan bu yağlar doğrudan kullanılmamakta, viskozitesini düşürücü bir takım biyokimyasal işlemlere tabi tutulmaktadırlar. Bu işlemlerden en çok uygulananı transesterifikasyondur.

Biyodizel konusunda gerekli üretim potansiyeline sahip olan ülkemizin hammadde ve üretim maliyetleri konusundaki sıkıntılarını giderememesi, biyodizel üretiminde dünyada söz sahibi ülkeler içerisinde yer almamızı engellemektedir. Bununla birlikte kayıt dışı ve standartlara uygun olmayan üretimin getirdiği olumsuzluklar biyodizelin gelişimini engellemektedir. Sonuç olarak biyodizel üretiminde kullanılan ham yağ ve yağlı tohumlardaki üretim açığı giderilerek, hammadde için gerekli altyapı hızla oluşturulmalıdır. Hizla artan enerji sorunumuzun çözümünde rol oynayabilecek biyodizelin gelişmesine katkı sağlayacak düzenlemeler planlı olarak hazırlanmalı ve ileriye dönük gelişmeler de dikkate alınarak uygulanmalidir.

\section{Kaynaklar}

Aksoy, L., 2010, Alternatif Enerji Kaynağ 1 Olarak Biyodizel ve Üretim Prosesleri. Taşit Teknolojileri Elektronik Dergisi, 45-52.

Alptekin, E., Çanakçı, M. 2006, Biyodizel ve Türkiye'nin Durumu, Mühendis ve Makine Dergisi, 47(561), 57-64.

Anonim., 2011a, TR 83 bölgesi yenilenebilir enerji raporu. http://www.ctso.org.tr/.

Anonim., 2011b, World Energy Council Conseil Mondial De L'energie For Sustainable Energy Turkish National Committee Dünya Enerji Konseyi Türk Milli Komitesi, enerji raporu 2011 Ankara.

Artukoğlu, B.D., 2006, "Hayvansal Atık Yağlardan Biyodizel Üretimi ve Özeliklerini Geliştirilmesi”, Yüksek Lisans Tezi, Gazi Üniversitesi, Fen Bilimleri Enstitüsü, Ankara.

Demirbaş, A., 2009, Biofuels from Agricultural Biomass. Energy Sources, Part A, 31, 1573-1582.

Enerji Tabii ve Kaynaklar Bakanlığg, 2012, 2011 Y1l Enerji Dengesi, http://www.enerji.gov.tr/ EKLENTI_ VIEW/index.php.

FAO, 2012, OECD, Food and Agriculture Organization of the United Nations. Pages.286 ISBN. 9789264173071 (PDF); 9789264173026 (print) DOI: 10.1787/agr_outlook-2012-en.

FAO, 2013, OECD and FAO Secretariats, http://www.fao.org/fileadmin/templat es/est/COMM

MARKETS_MONITORING/Oilcrop s/Documents/OECD_Reports/OECD _2013_22_biofuels_proj.pdf.

Güler, K., 2008, Biyodizel Teknolojisi, Sistem Tasarımı ve Deneysel Olarak 
Biyodizel Üretimi, S.D.Ü. Fen Bilimler Enstitüsü, Isparta, Yüksek Lisans Tezi.

Hart Energy, 2012, Global Biofuels Outlook: Policy, Market and Technology Trends, Hart Energy and Breakfast Series.

İşler, A., 2012, Biyoyakıt Teknolojileri. İstanbul Teknik Üniversitesi, İstanbul.

Koç, M., 2011, Biyodizel Üretimine Uygun Türkiye'de Yetişen ve Yetişebilecek Bitkilerin ve Biyodizel Teknolojilerinin Belirlenmesi, Yıldız Teknik Üniversitesi, Fen Bilimler Enstitüsü, İstanbul,

Mutlu, L., Yavuz, H. Bayrakçeken, H., 2006, "Biyodizel Yakitların Performanslarının Karşılaştırılması", 9. Yanma Sempozyumu, 16-17 Kasım 2006, Kırıkkale, s.40-49

Oğuz, H., Öğüt, H., 2004, Çiftçi Şartlarında Uygun Bir Biyodizel Tesisinin Tasarımı,Tarımsal Mekanizasyon 22. Ulusal Kongresi, 08-10 Eylül 2004, Aydın, s.55.

Öğüt, H., Oğuz, H., 2006, Üçüncü Milenyum Yakıtı Biyodizel, Nobel Yayın Dağıtım, Ankara.

Öztürk, Ö., 2007, Dizel Motorlarında Karışımsız Olarak Kullanılan Biyodizellerin Motor Performansina Olan Etkilerinin Araştırılması, Yıldız Teknik Üniversitesi, Fen Bilimleri Enstitüsü, İstanbul, Yüksek Lisans Tezi.

Sabanc1, A., Yaşar, B., Öztürk, H. H., Ören, M. N., Atal, M., 2010, Türkiyede Biyodizel ve Biyoetonal Üretiminin Tarım Sektörü Açısından Değerlendirilmesi. Çukurova Üniversitesi, Adana.

TÜİK,2012.www.tuik.gov.tr/preistatistiktablo .do?istab_id=1562.
Türkyılmaz, O. ve Özgiresun, C., 2012, Türkiye'nin Enerji Görünümü, Makine Mühendisleri Odası Raporu, Yayın No. MMO/588

Uğur, Edip, A., 2012. Türkiye'de Yağlı Tohum Bitkileri Üretimi ve Bitkidel Yağ Sanayisi. YABİTED 1. Bitkisel Yağ kongresi 12-14 Nisan, Adana.

Ulusoy, Y., 1999, “Ayçiçeği, Kolza, Pamuk ve Soya Yağlarının Dizel Motorlarında Yakıt Olarak Kullanım Olanaklarının belirlenmesi Üzerine Karşılaştırmalı Bir Araştırma”, Uludağ Üniversitesi Fen Bilimleri Enstitüsü, Bursa, Doktora Tezi, 6$11 \mathrm{~s}$.

URL-1, Toplumsal Analiz. Retrieved from http://www.toplumsalanaliz.net/2012 /02/biyodizel-biyodizel-bastabrezilya.html. Ekim 2013.

URL-2, Cevreonline. Retrieved 2013, from http://www.cevreonline.com. Ekim 2013.

URL-3, T.C. Enerji ve Tabi Kaynaklar Bakanlğı. Retrieved from Dünya'da ve Türkiye'de enerji görünümü:http://www.enerji.gov.tr/y ayinlar_raporlar/Dunyada_ve_Turkiy ede_Enerji_Gorunumu.pdf. Ekim 2013.

URL-4, 2012, Bitkisel Yă̆ Borsas1. Retrieved, from http://www.bitkiselyagborsasi.com/tr $/$ default.asp? sayfa=goster $\&$ no $=\mathrm{d} 0$. Ekim 2013.

URL-5. 2013, AHMET TOPRAKÇI MCT. Retrieved from http://ahmettoprakci.net/category/ makaleler-yazilar/3rd-party/

URL-6, Albiyobir. Retrieved, 2013, from http://www.albiyobir.org.tr/biyodizel .htm. Ekim 2013. 
URL-7, ENERGY.GOV Office of Energy Efficiency \& Renewable Energy. Retrieved 2013, from http://www.afdc.energy.gov/fuels/bio diesel_basics.html. Ekim 2013.

URL-8, Yenilenebilir Enerji Genel Müdürlüğü. Retrieved 2013, from http://www.eie.gov.tr/eieweb/turkce/YEK/biyoenerji/02biyodizel/bd_yakit_ozellik.html. 2011.

Vogel, C. 1999, "Coals Role in Electrical Power Generation: Will It Remain Competitive", Proceedings of the Technical Conference on Coal Utilization and Fuel Systems, Coal and Slurry Technology Association, p.13-24. 